\title{
PENINGKATAN MUTU BIJIH BAUKSIT TAYAN MENGGUNAKAN PEMISAH MAGNETIK
}

\author{
Upgrading Tayan Bauxite Ore Using Magnetic Separator
}

\author{
STEFANUS S. CAHYONO ${ }^{1,2}$, ILDREM SYAFRI ${ }^{2}$ dan JOHANES HUTABARAT ${ }^{2}$ \\ ${ }^{1}$ Puslitbang Teknologi Mineral dan Batubara \\ Jalan Jenderal Sudirman 623 Bandung 40211 \\ Telp. (022) 603043, Fax. (022) 6003373 \\ e-mail: stefanus.suryo2017@gmail.com \\ 2 Fakultas Teknik Geologi, Universitas Padjadjaran \\ Jalan Raya Bandung Sumedang KM 21, Jatinangor, \\ Kabupaten Sumedang, Jawa Barat 45363
}

\begin{abstract}
ABSTRAK
Sumberdaya bauksit yang ada di Tayan, Kalimantan Barat belum dimanfaatkan secara optimal dan perlu dilakukan peningkatan nilai tambah bauksit melalui proses pencucian dan pengolahan, sehingga perlu dilakukan pengkajian peningkatan mutu bijih bauksit. Percontoh bijih bauksit yang diambil dari daerah Tayan memiliki kadar $\mathrm{SiO}_{2}$ total 11,55\%, $\mathrm{Al}_{2} \mathrm{O}_{3} 43,64 \%, \mathrm{Fe}_{2} \mathrm{O}_{3}$ 9,63\%. Proses peningkatan mutu (upgrading) bijih bauksit bertujuan untuk menaikkan kadar bauksit agar memenuhi persyaratan alumina di atas 51\% $\mathrm{Al}_{2} \mathrm{O}_{3}$, maksimum 3\% $\mathrm{SiO}_{2}$ dan maksimum $7 \% \mathrm{Fe}_{2} \mathrm{O}_{3}$ untuk bahan baku alumina. Tahapan proses scrubbing meliputi pemercontohan, scrubbing, pengayakan, pengeringan, penimbangan, penggerusan, pemisah magnetik dan analisis kimia. Parameter mutu yang digunakan untuk menilai keberhasilan adalah persen kumulatif ukuran butiran + $2 \mathrm{~mm}$ (+ 10 mesh), perolehan $\mathrm{Al}_{2} \mathrm{O}_{3}$, kadar $\mathrm{SiO}_{2}$ total, $\mathrm{Al}_{2} \mathrm{O}_{3}$, dan $\mathrm{Fe}_{2} \mathrm{O}_{3}$. Uji coba proses pencucian-magnetik separator ini telah memberikan hasil yang baik ditinjau dari peningkatan kadar $\mathrm{Al}_{2} \mathrm{O}_{3}$ dan perolehan $\mathrm{Al}_{2} \mathrm{O}_{3}$. Kadar $\mathrm{Al}_{2} \mathrm{O}_{3}$ hasil uji coba berkisar antara $57,29-59,78 \%$ dengan perolehan berkisar 69,67-85,58\%. Bauksit tercuci-magnetik separator yang dihasilkan telah meningkatkan mutu bijih bauksit sebagai bahan baku pembuatan alumina melalui proses Bayer.
\end{abstract}

Kata kunci : bauksit, upgrading, scrubbing, pemisah magnetik, konsentrat alumina.

\begin{abstract}
Bauxite resources in Tayan, West Kalimantan have not been used optimally and it is necessary to increase the added value of bauxite through washing and processing processes so that an assessment of the quality of bauxite ore needs to be carried out. Bauxite ore samples taken from the Tayan area have a total $\mathrm{SiO}_{2}$ content of $11.55 \%, \mathrm{Al}_{2} \mathrm{O}_{3} 43.64 \%, \mathrm{Fe}_{2} \mathrm{O}_{3} 9.63 \%$. The upgrading process of ore is aimed at increasing bauxite grade to meet alumina requirements above $51 \% A I_{2} \mathrm{O}_{3}$, maximum $3 \%$ $\mathrm{SiO}_{2}$ and a maximum of $7 \% \mathrm{Fe}_{2} \mathrm{O}_{3}$ for alumina raw materials. The stages of the scrubbing process include sampling, scrubbing, screening, drying, weighing, grinding, magnetic separator and chemical analysis. The quality parameters used to assess the results are percent cumulative grain size $+2 \mathrm{~mm}$ (+ 10 mesh), $\mathrm{Al}_{2} \mathrm{O}_{3}$ recovery, the total content of $\mathrm{SiO}_{2}, \mathrm{Al}_{2} \mathrm{O}_{3}$, and $\mathrm{Fe}_{2} \mathrm{O}_{3}$. Magnetic separation and
\end{abstract}


washing processes have given good results in terms of increasing $\mathrm{Al}_{2} \mathrm{O}_{3}$ grade and recovery of $\mathrm{Al}_{2} \mathrm{O}_{3}$. The grade resulted from the experiment in the range of 57.29 to $59.78 \%$ of $\mathrm{Al}_{2} \mathrm{O}_{3}$ with the $\mathrm{Al}_{2} \mathrm{O}_{3}$ recovery ranging from 69.67 to $85.58 \%$. The washed-magnetic separation process has improved the quality of bauxite ore as raw material for making alumina through the Bayer process.

Keywords: bauxite, upgrading, scrubbing, magnetic separator, alumina concentrate.

\section{PENDAHULUAN}

Indonesia memiliki sumberdaya bijih bauksit yang melimpah sebesar 3.617.770.882 ton dengan jumlah cadangan sebesar 1.257.169.367 ton berdasarkan data dari Kementerian Energi dan Sumber Daya Mineral (ESDM) (Pusat Sumber Daya Geologi, 2015). Sumberdaya bauksit tersebut selama ini belum dimanfaatkan secara optimal dan perlu dilakukan peningkatan nilai tambah bijih bauksit melalui proses pencucian, pengolahan dan pemurnian.

Dengan adanya Peraturan Menteri ESDM No. 05 tahun 2017 tentang peningkatan nilai tambah bijih bauksit maka untuk memenuhi kebutuhan PT. Inalum, bijih bauksit tersebut perlu dilakukan pencucian, pengolahan dan pemurnian (Bott dan Langeloh, 2015). Satusatunya aluminium smelter di Indonesia milik PT. Inalum masih mengimpor alumina, produk lanjutan dari bauksit. Bauksit hasil pencucian digunakan untuk mendapatkan bahan baku alumina, sebagian lainnya untuk bahan abrasif, semen, refraktori dan bahan kimia antara lain tawas, fero sulfat, besi klorida, poli aluminium klorida (PAC), dan poli aluminium silikat sulfat (PASS) yang banyak dimanfaatkan pada penjernihan air di PDAM dan industri (Passos dan Rodrigues, 2016; Gupta, 2017; King, 2017).

Bauksit sebagai bahan baku untuk pembuatan alumina yang selanjutnya digunakan sebagai bahan pembuatan logam aluminium memiliki persyaratan alumina di atas $51 \% \quad \mathrm{Al}_{2} \mathrm{O}_{3}$, maksimum $3 \% \mathrm{SiO}_{2}$ dan maksimum $7 \%$ $\mathrm{Fe}_{2} \mathrm{O}_{3}$; untuk bahan baku kimia (chemical) kandungan alumina lebih dari 58\%, kandungan oksida besi serendah mungkin (Husaini $d k k ., 2014$ ).

Proses peningkatan kadar dari bijih bauksit alumina umumnya didahului dengan peremukan yang dilanjutkan dengan scrubbing dan pengayakan untuk menurunkan silikanya dan membersihkan slime yang melekat pada bauksit (Smith, 2008; Nandi, Mahadevan dan Ramachandran, 2012). Tujuan penelitian ini untuk menaikkan kadar bauksit agar memenuhi persyaratan alumina di atas $51 \%$ $\mathrm{Al}_{2} \mathrm{O}_{3}$, maksimum $3 \% \mathrm{SiO}_{2}$ dan maksimum 7 $\% \mathrm{Fe}_{2} \mathrm{O}_{3}$ untuk bahan baku alumina. Penelitian ini dilakukan di laboratorium Puslitbang tekMIRA.

\section{METODE}

Bahan baku bijih bauksit yang digunakan untuk percobaan berasal dari daerah Tayan, Kalimantan Barat. Gambar 2 menunjukkan fotomikrograf percontoh bauksit Tayan, tampak mineral gibsit, magnetit, hematit, limonit dan hematit, membentuk urat-urat yang terdapat di dalam bongkah bauksit. Selain itu terkandung pula mineral kuarsa, mika dan lempung yang berikatan dengan gibsit.

\section{Peralatan}

Peralatan yang digunakan untuk penelitian meliputi:

- 1 unit jaw crusher (kapasitas 200-250 $\mathrm{kg} / \mathrm{jam}$, ukuran umpan 4", dan produk 1")

- 1 unit roll crusher (kapasitas 20-40 kg/jam)

- 1 unit ring mill ( kapasitas 1 kg/jam)

- 1 unit scrubber (volume sekitar 50 liter)

- 6 macam ayakan masing masing 1 buah (ukuran lubang $1 \mathrm{~cm}, 2,00 \mathrm{~mm}, 0,5 \mathrm{~mm}$ (35 mesh), 0,25 mm (60 mesh), 0,15 $\mathrm{mm}$ (100 mesh) dan 0,106 mm (150 mesh)

- 1 unit oven pengering (suhu maksimum $\left.250^{\circ} \mathrm{C}\right)$

- 1 unit timbangan (berat maksimum $25 \mathrm{~kg}$ )

\section{Prosedur Percobaan}

Prosedur percobaan pencucian bijih bauksit dan pemisah magnetik dapat dilihat pada Gambar 1. 


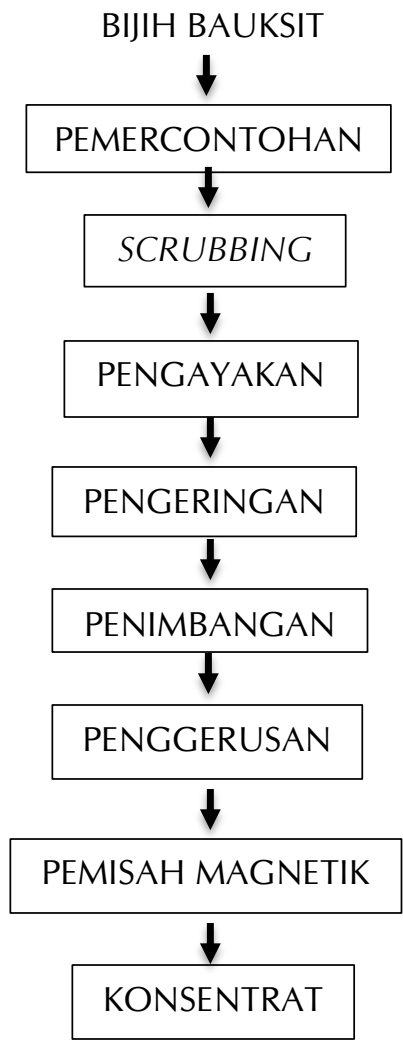

Gambar 1. Bagan alir proses percobaan scrubbing dan pemisah magnetik

\section{HASIL DAN PEMBAHASAN}

Hasil percobaan yang akan dibahas meliputi kondisi bahan baku dan percobaan magnetik separator terhadap percontoh bauksit Tayan yang meliputi aspek distribusi ukuran butiran, komposisi kimia dan perolehan $\mathrm{Al}_{2} \mathrm{O}_{3}$.

\section{Bahan Baku}

Berdasarkan data komposisi kimia bahan baku yang disajikan pada Tabel 1, bijih bauksit asal Tayan belum memenuhi spesifikasi sebagai bahan baku alumina pada proses Bayer yang mensyaratkan kandungan minimal $51 \% \mathrm{Al}_{2} \mathrm{O}_{3}$, maksimum $3 \% \mathrm{SiO}_{2}$ dan maksimum $7 \%$ $\mathrm{Fe}_{2} \mathrm{O}_{3}$ sedangkan untuk bahan baku kimia memerlukan persyaratan yang lebih tinggi, yaitu alumina $55 \%$ (min), silika $5-18 \%$, oksida besi $2 \%$ (maks), oksida titan 0-6\% (Smith, 2008). Oleh karena itu, penelitian peningkatan mutu lebih dititikberatkan pada peningkatan kadar alumina dan kadar $\mathrm{SiO}_{2}$ untuk dapat memenuhi spesifikasi sebagai bahan baku alumina pada proses Bayer.
Tabel 1. Komposisi kimia bahan baku penelitian

\begin{tabular}{llccc}
\hline No & Percontoh & $\begin{array}{c}\mathrm{SiO}_{2} \\
\text { total } \\
(\%)\end{array}$ & $\begin{array}{c}\mathrm{Al}_{2} \mathrm{O}_{3} \\
(\%)\end{array}$ & $\begin{array}{c}\mathrm{Fe}_{2} \mathrm{O}_{3} \\
(\%)\end{array}$ \\
\hline 1 & Tayan & 11,55 & 43,64 & 9,63 \\
\hline
\end{tabular}

Pada Tabel 2 dapat dilihat kadar komposisi senyawa oksida yang dimiliki oleh percontoh Tayan. Spesifikasi bauksit sebagai bahan baku berbagai produk jarang yang mencantumkan persyaratan unsur, kecuali untuk kegunaan khusus, seperti untuk bahan baku bubuk aluminium oksida, fluks pada pabrik baja (Husaini dan Cahyono, 2009). Berdasarkan berbagai spesifikasi kegunaan khusus tersebut, percontoh Tayan memiliki kadar oksida senyawa relatif kecil dan tidak menunjukkan pengaruh terhadap mutu bijih bauksit. Pada Tabel 3 dapat dilihat analisis liberasi, sedangkan hasil fotomikrograf percontoh Tayan dapat dilihat pada Gambar 2.

Tabel 2. Komposisi kimia senyawa oksida percontoh Tayan-1

\begin{tabular}{cc}
\hline Komponen & $(\%)$ \\
\hline $\mathrm{V}_{2} \mathrm{O}_{5}$ & 0,121 \\
$\mathrm{MgO}$ & 0,0208 \\
$\mathrm{MnO}$ & 0,0382 \\
$\mathrm{CaO}$ & 0,0297 \\
$\mathrm{P}_{2} \mathrm{O}_{5}$ & 0,0248 \\
\hline $\mathrm{Cl}$ & 0,0174 \\
$\mathrm{Ga}_{2} \mathrm{O}_{3}$ & 0,0061 \\
$\mathrm{~K}_{2} \mathrm{O}$ & 0,0036 \\
$\mathrm{ZnO}_{2}$ & 0,0032 \\
$\mathrm{~S}_{2} \mathrm{O}_{3}$ & 0,0031 \\
\hline
\end{tabular}

Tabel 3. Hasil analisis derajat liberasi percontoh bauksit Tayan

\begin{tabular}{cc}
\hline Ukuran fraksi(mesh) & Derajat liberasi $(\%)$ \\
\hline$-10+35$ & 60,60 \\
$-35+60$ & 65,21 \\
$-60+100$ & 81,86 \\
$-100+150$ & 89,37 \\
-150 & 92,25 \\
\hline
\end{tabular}

\section{Percobaan Scrubbing}

Proses scrubbing ini bertujuan untuk melepaskan partikel-partikel pengotor yang menempel pada permukaan bijih bauksit yang umumnya berukuran halus $<2 \mathrm{~mm}$ (Tsamo, 
Kofa dan Kamga, 2017). Dengan memisahkan partikel berukuran $<2 \mathrm{~mm}$, kadar $\mathrm{Al}_{2} \mathrm{O}_{3}$ akan meningkat dan kandungan senyawa pengotor seperti $\mathrm{Fe}_{2} \mathrm{O}_{3}$ dan $\mathrm{SiO}_{2}$ akan menurun. Proses scrubbing (pengayakan dan pencucian)

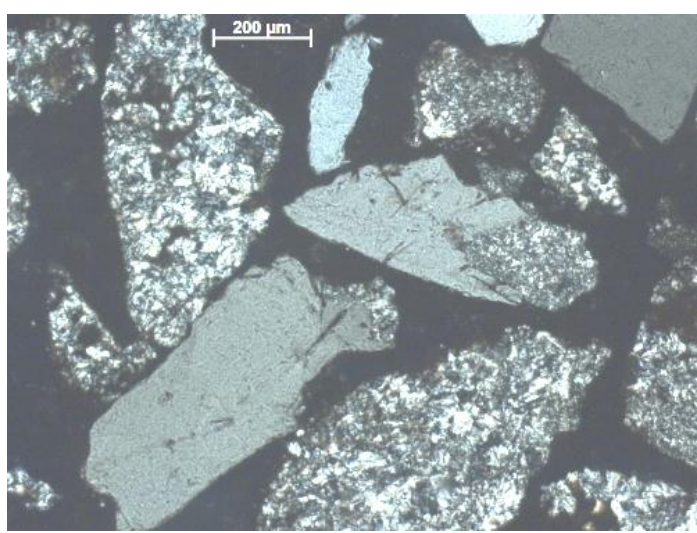

Gambar 2a. Fotomikrograf sayatan tipis bauksit Tayan fraksi $+35 \#(\mathrm{G}=$ Gibsit $),(K=$ Kuarsa $)$

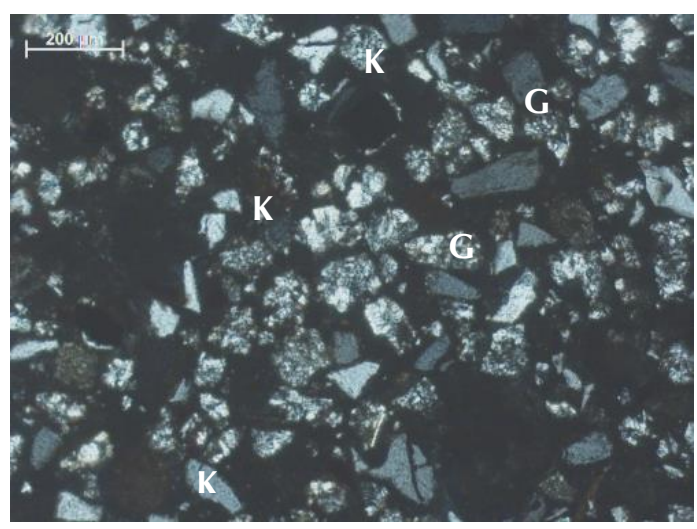

Gambar 2c. Fotomikrograf sayatan tipis bauksit Tayan fraksi $-60+100 \#(G=$ Gibsit), (K=Kuarsa) merupakan cara yang efektif dalam menurunkan kandungan silika yang merupakan pengotor dalam bauksit, karena silika umumnya terkonsentrasi pada fraksi butiran halus (Smith, 2008).

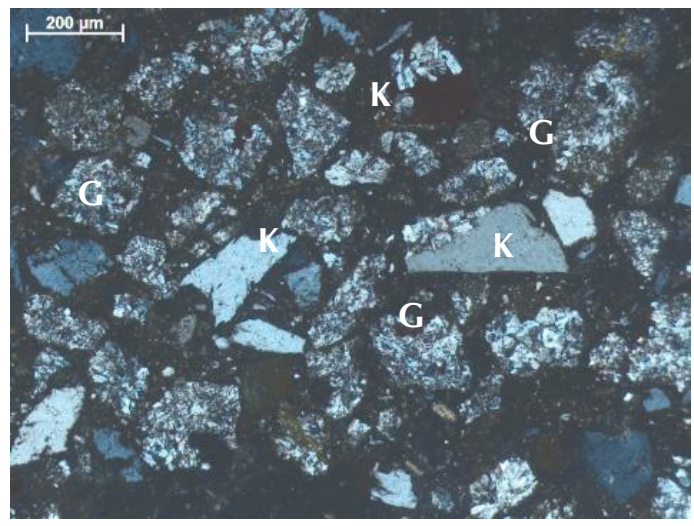

Gambar 2b. Fotomikrograf sayatan tipis bauksit Tayan fraksi $-35+60 \#(G=$ Gibsit), $(K=$ Kuarsa)

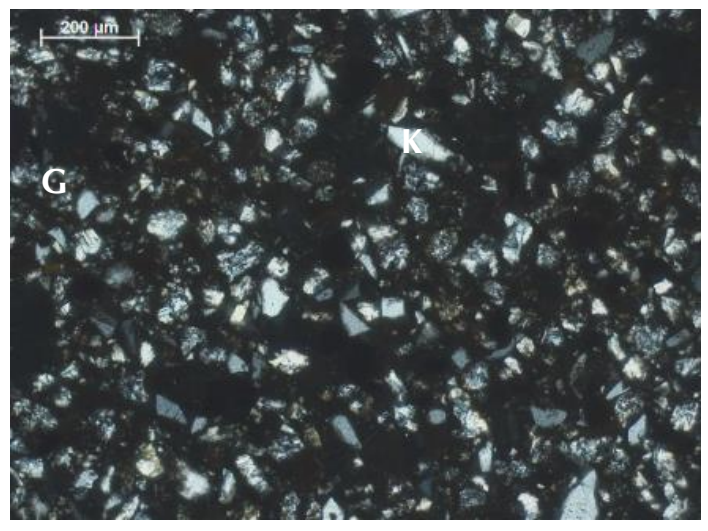

Gambar 2d. Fotomikrograf sayatan tipis bauksit Tayan fraksi $-100+150 \#$ ( $G=$ Gibsit), (K=Kuarsa)

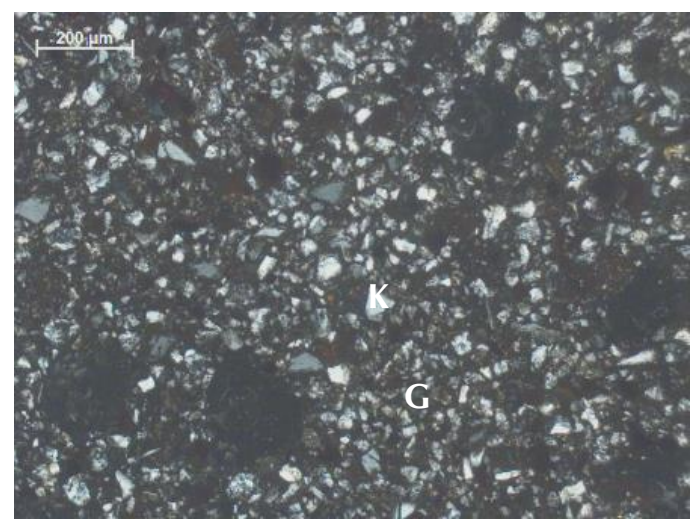

Gambar 2e. Fotomikrograf sayatan tipis bauksit Tayan fraksi -150\# ( $\mathrm{G}=\mathrm{Gibsit})$, (K=Kuarsa) 


\section{Distribusi Ukuran Butiran}

Pada percontoh yang berasal dari Tayan, sebelum scrubbing memiliki fraksi ukuran butiran $+2 \mathrm{~mm}$ kumulatif sebesar $78,72 \%$, sedangkan setelah melalui proses scrubbing fraksi ukuran butiran $+2 \mathrm{~mm}$ yang dihitung kumulatif turun menjadi $71,99 \%$ setelah melalui pengayakan. Hal ini disebabkan oleh terlepasnya partikel-partikel pengotor yang menempel pada permukaan bijh bauksit setelah dilakukan proses scrubbing.

\section{Komposisi Kimia}

Pada fraksi $+2 \mathrm{~mm}$ yang dihitung kumulatif percontoh asal (head sample) memiliki kadar $\mathrm{SiO}_{2 \text { tot }} 11,55 \%, \mathrm{Al}_{2} \mathrm{O}_{3} 43,64 \%, \mathrm{Fe}_{2} \mathrm{O}_{3} 9,63$ $\%$, dan setelah scrubbing memiliki kadar $\mathrm{SiO}_{2}$ $5,35 \%, \mathrm{Al}_{2} \mathrm{O}_{3} 45,73 \%, \mathrm{Fe}_{2} \mathrm{O}_{3} 8,01 \%$ akibat hilangnya mineral pengotor. Kadar bauksit setelah scrubbing belum memenuhi spesifikasi sebagai bahan baku alumina, maupun bahan baku chemical. Ditinjau dari kadar alumina dan besinya, hasil scrubbing ini belum memenuhi syarat untuk bahan baku alumina untuk proses Bayer yang mensyaratkan kandungan $\mathrm{Al}_{2} \mathrm{O}_{3}$ minimum $51 \%$, dan kadar $\mathrm{Fe}_{2} \mathrm{O}_{3}$ maksimum 7\% (Husaini dan Cahyono, 2009). Oleh karena itu perlu dilakukan proses pengolahan bijih bauksit tersebut agar dapat memenuhi persyaratan sebagai bahan baku pembuatan alumina melalui proses Bayer.

\section{Percobaan Magnetic separator}

Proses magnetic separator ini bertujuan untuk memisahkan satu mineral atau lebih dengan mineral lainnya yang memanfaatkan perbedaan sifat kemagnetan dari mineral-mineral yang dipisahkan. Hasil percobaan magnetic separator menggunakan variasi kuat medan magnit mulai dari 2.500, 5.000, 7.500 dan 10.000 gauss dapat dilihat pada Gambar 3 sampai dengan Gambar 6.

\section{Pengaruh Ukuran Butir terhadap Perolehan dan Kadar $\mathrm{Al}_{2} \mathrm{O}_{3}$ dan $\mathrm{Fe}_{2} \mathrm{O}_{3}$ dalam Produk Non-magnetik 2.500 gauss}

Gambar 3 menunjukkan data hasil proses magnetic separator pada kuat medan magnet 2.500 gauss dengan variari ukuran butir +35 , $-35+60,-60+100,-100+150$ dan -150 mesh.
Kondisi percobaan magnetic separator yang terbaik diperoleh pada ukuran butir $-35+60$ mesh, karena pada ukuran butir tersebut $\mathrm{Al}_{2} \mathrm{O}_{3}$ sudah terliberasi sebesar $65,21 \%$, sehingga kadar $\mathrm{Al}_{2} \mathrm{O}_{3}$ meningkat dari $43,64 \%$ menjadi $56,41 \%$, namun kadar $\mathrm{Fe}_{2} \mathrm{O}_{3}$ masih tinggi yaitu $7,87 \%$. Masih tingginya kadar $\mathrm{Fe}_{2} \mathrm{O}_{3}$ ini karena kuat medan magnet yang digunakan masih relatif rendah, sehingga tidak dapat menarik kandungan mineral besi seperti hematit yang memiliki sifat kemagnetan yang rendah dan belum memenuhi syarat sebagai bahan baku alumina.

Pada batasan ukuran butir mulai dari $60+100,-100+150$ dan -150 mesh, kadar $\mathrm{Al}_{2} \mathrm{O}_{3}$ cenderung turun karena material berukuran butir terlalu halus akan melayanglayang dan tidak tertarik oleh medan magnet, sehingga kadar $\mathrm{Fe}_{2} \mathrm{O}_{3}$ dalam produk nonmagnetik masih tetap tinggi. Perolehan $\mathrm{Al}_{2} \mathrm{O}_{3}$ yang tinggi dengan kadar besi yang tinggi pada produk non-magnetik diperoleh pada kondisi kuat medan magnit 2500 gauss dengan hasil perolehan $\mathrm{Al}_{2} \mathrm{O}_{3} 53,78 \%$, dengan kadar $\mathrm{Al}_{2} \mathrm{O}_{3}$ $55,92 \%$, kadar besi $7,25 \%$.

Pengaruh Ukuran Butir terhadap Perolehan dan Kadar $\mathrm{Al}_{2} \mathrm{O}_{3}$ dan $\mathrm{Fe}_{2} \mathrm{O}_{3}$ dalam Produk Non-magnetik 5000 gauss

Gambar 4 menunjukkan data hasil proses magnetic separator pada kuat medan magnet 5.000 gauss dengan variari ukuran butir +35 , $-35+60, \quad-60+100,-100+150$ dan -150 mesh.Kondisi percobaan magnetic separator yang terbaik diperoleh pada ukuran butir $35+60$ mesh pada 5.000 gauss karena pada ukuran butir tersebut bauksit sudah terliberasi sebesar 65,21 \% sehingga kadar $\mathrm{Al}_{2} \mathrm{O}_{3}$ meningkat dari $43,64 \%$ menjadi $57,61 \%$, dan kadar $\mathrm{Fe}_{2} \mathrm{O}_{3}$ mengalami penurunan dari $\mathrm{Fe}_{2} \mathrm{O}_{3}$ 9,62\% menjadi 5,77\% karena pada ukuran butir tersebut kuat medan magnet dapat menarik sifat kemagnetan mineral hematit dalam bauksit.

Pada batasan ukuran butir tertentu dari -60 $+100,-100+150$ dan -150 mesh kadar $\mathrm{Al}_{2} \mathrm{O}_{3}$ cenderung turun karena ukuran butir terlalu halus sehingga melayang tidak tertarik oleh medan magnet, sedangkan kadar $\mathrm{Fe}_{2} \mathrm{O}_{3}$ cenderung tinggi karena mineral besi berada di bawah mineral $\mathrm{Al}_{2} \mathrm{O}_{3}$ yang halus sehingga tidak tertatik oleh medan magnet. Perolehan $\mathrm{Al}_{2} \mathrm{O}_{3}$ 
dalam produk non-magnetik dengan gauss $5.000 \mathrm{Al}_{2} \mathrm{O}_{3} \quad 65,23 \%$ dengan kadar $\mathrm{Al}_{2} \mathrm{O}_{3}$ $56,83 \%$, kadar besi 5,52 \%.

Pengaruh Ukuran Butir terhadap Perolehan dan Kadar $\mathrm{Al}_{2} \mathrm{O}_{3}$ dan $\mathrm{Fe}_{2} \mathrm{O}_{3}$ dalam Produk Non-magnetik 7500 gauss

Gambar 5 menunjukkan data hasil proses magnetic separator pada kuat medan magnet 7500 gauss dengan variasi ukuran butir $+35,-$ $35+60,-60+100,-100+150$ dan -150 mesh.
Kondisi percobaan magnetic separator yang memberikan hasil yang terbaik diperoleh pada ukuran butir $-35+60$ mesh pada 7500 gauss. Pada ukuran butir tersebut bauksit sudah terliberasi sebesar 65,21\% sehingga kadar $\mathrm{Al}_{2} \mathrm{O}_{3}$ meningkat dari $43,64 \%$ menjadi 59,78 $\%$, dan kadar $\mathrm{Fe}_{2} \mathrm{O}_{3}$ mengalami penurunan dari $\mathrm{Fe}_{2} \mathrm{O}_{3}$ 9,62 \% menjadi 4,51\% karena pada ukuran butir tersebut kuat medan magnet dapat menarik sifat kemagnetan dari bauksit.

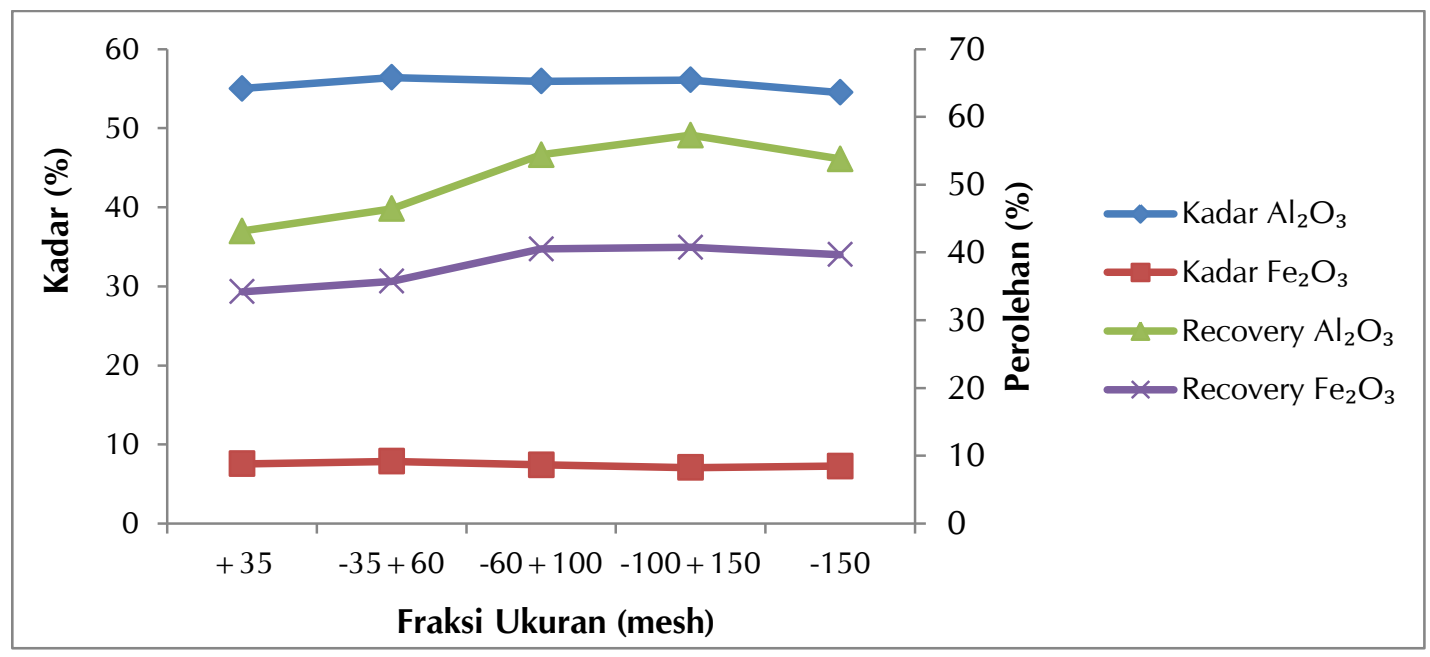

Gambar 3. Hasil percobaan proses magnetic separator pada kekuatan medan magnet 2.500 gauss

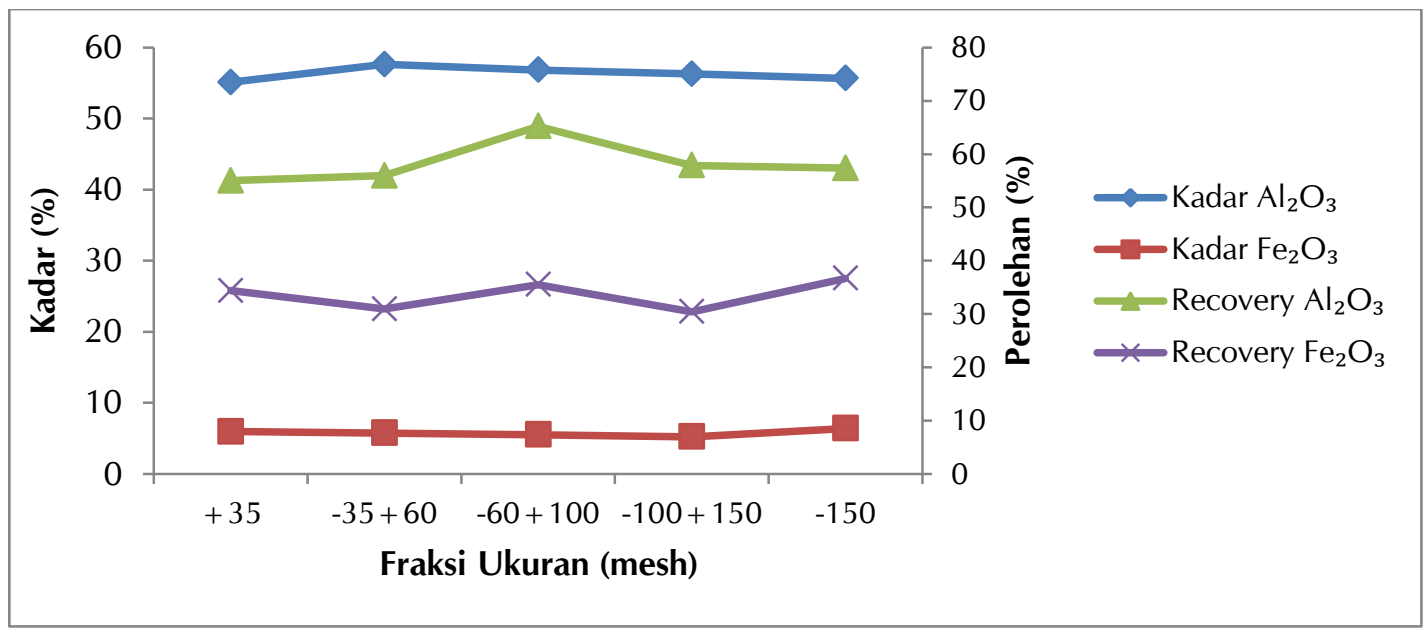

Gambar 4. Hasil percobaan proses magnetic separator pada kekuatan medan magnet 5.000 gauss 


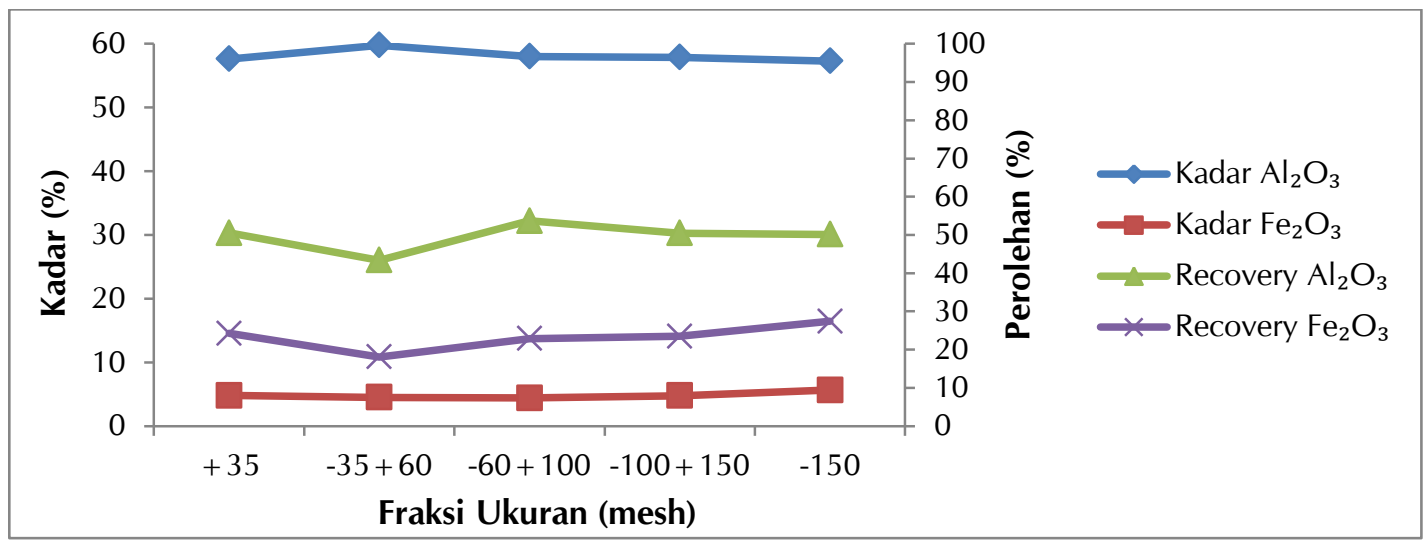

Gambar 5. Hasil percobaan proses pemisah magnetik pada kekuatan medan magnet 7.500 gauss

Pada batasan ukuran butir tertentu dari $60+100,-100+150$ dan -150 mesh kadar $\mathrm{Al}_{2} \mathrm{O}_{3}$ cenderung turun karena ukuran butir terlalu halus sehingga melayang tidak tertarik oleh medan magnet, sedangkan kadar $\mathrm{Fe}_{2} \mathrm{O}_{3}$ cenderung tinggi karena mineral besi berada di bawah mineral $\mathrm{Al}_{2} \mathrm{O}_{3}$ yang halus sehingga tidak tertarik oleh medan magnet.

Perolehan $\mathrm{Al}_{2} \mathrm{O}_{3}$ dalam produk non-magnetik dengan gauss $7.500 \mathrm{Al}_{2} \mathrm{O}_{3} \quad 53,70 \%$ dengan kadar $\mathrm{Al}_{2} \mathrm{O}_{3} 58,01 \%$, kadar besi $4,41 \%$.

\section{Pengaruh Ukuran Butir terhadap Perolehan dan Kadar $\mathrm{Al}_{2} \mathrm{O}_{3}$ dan $\mathrm{Fe}_{2} \mathrm{O}_{3}$ dalam Produk Non-magnetik 10.000 gauss}

Gambar 6 menunjukkan data hasil proses magnetic separator pada kuat medan magnet 10.000 gauss dengan variasi ukuran butir +35 , $-35+60,-60+100,-100+150$ dan -150 mesh. Kondisi hasil percobaan magnetic separator pada ukuran fraksi $-35+60$ mesh pada 10000 gauss memberikan hasil yang terbaik, karena pada ukuran butir tersebut $\mathrm{Al}_{2} \mathrm{O}_{3}$ sudah terliberasi sebesar $65,21 \%$ sehingga kadar $\mathrm{Al}_{2} \mathrm{O}_{3}$ dalam produk non-magnetik meningkat dari $43,64 \%$ menjadi $57,86 \%$, dan kadar $\mathrm{Fe}_{2} \mathrm{O}_{3}$ mengalami penurunan dari $\mathrm{Fe}_{2} \mathrm{O}_{3}$ 9,62 $\%$ menjadi $3,91 \%$. Hal ini dikarenakan pada ukuran butir tersebut mineral hematit dapat tertarik oleh medan magnet. Pada batasan ukuran butir tertentu dari $-60+100,-100+150$ dan -150 mesh kadar $\mathrm{Al}_{2} \mathrm{O}_{3}$ cenderung turun karena ukuran butir terlalu halus sehingga melayang tidak tertarik oleh medan magnet, sedangkan kadar $\mathrm{Fe}_{2} \mathrm{O}_{3}$ cenderung tinggi karena mineral besi berada di bawah mineral $\mathrm{Al}_{2} \mathrm{O}_{3}$ yang halus sehingga tidak tertarik oleh medan magnet. Perolehan $\mathrm{Al}_{2} \mathrm{O}_{3}$ dalam produk non-magnetik dengan gauss $10.000 \quad \mathrm{Al}_{2} \mathrm{O}_{3}$ $50,26 \%$ dengan kadar $\mathrm{Al}_{2} \mathrm{O}_{3} 55,89 \%$, kadar besi $3,31 \%$.

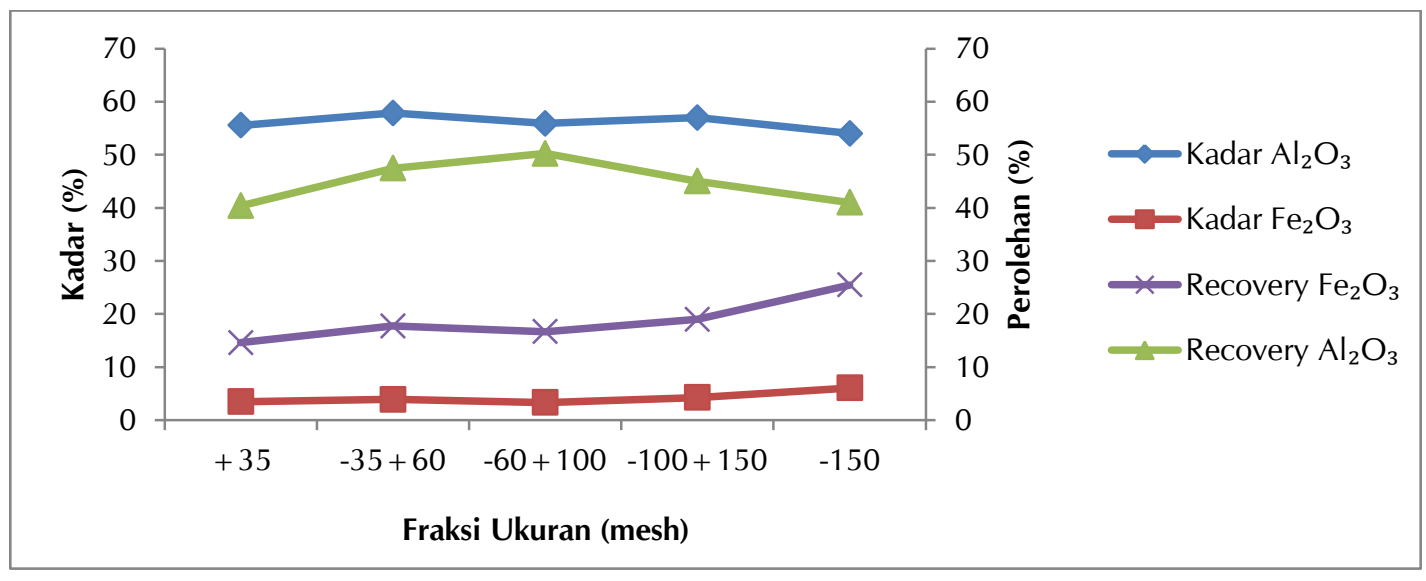

Gambar 6. Hasil percobaan proses pemisah magnetik pada kekuatan medan magnet 10.000 gauss 


\section{KESIMPULAN DAN SARAN}

\section{Kesimpulan}

Dari hasil percobaan bauksit diketahui bahwa bijih bauksit asal Tayan dominan mengandung mineral gibsit dan kuarsa, dengan ukuran fraksi butiran $+2 \mathrm{~mm}$ sebesar $78,72 \%$ dengan kandungan $\mathrm{Al}_{2} \mathrm{O}_{3} 43,64 \%$, $\mathrm{Fe}_{2} \mathrm{O}_{3}$ 9,63\%, dan $\mathrm{SiO}_{2}$ 11,55\%. Sebelum dilakukan proses pemisahan dengan pemisah magnetic kadar $\mathrm{Al}_{2} \mathrm{O}_{3}<51 \%$ dan kandungan pengotor $\mathrm{Fe}_{2} \mathrm{O}_{3}$ masih tinggi, setelah dilakukan proses pemisahan dengan pemisah magnetik pada kuat medan magnet mulai dari 5000, 7500, 10000 gauss kadar $\mathrm{Al}_{2} \mathrm{O}_{3}>51 \%$ untuk semua ukuran fraksi dan kandungan pengotor $\mathrm{Fe}_{2} \mathrm{O}_{3}<7 \%$, dari hasil percobaan pemisah magnetik terbaik diperoleh pada kekuatan medan magnet 7500 gauss dengan ukuran fraksi $-35+60$ mesh menghasilkan produk yang telah memenuhi syarat untuk bahan baku alumina.

\section{Saran}

Percobaan peningkatan mutu bijih bauksit perlu dilanjutkan lagi dengan menggunakan metode lain seperti flotasi untuk dapat meningkatkan nilai tambah bauksit.

\section{DAFTAR PUSTAKA}

Bott, R. and Langeloh, T. (2015) 'Process options for the filtration and washing of bauxite residue', in Bauxite Residue Valorisation and Best Practices. Leuven, Belgium: $\mathrm{SIM}^{2} \mathrm{KU}$ Leuven, pp. 61-70. Available at: http://conference2015.redmud.org/wpcontent/uploads/2015/10/Reinhard-BOTTsecure.pdf.

Gupta, D. (2017) India's mineable bauxite reserve at $0.656 \mathrm{bln}$ tonnes can last next 25 years, www.alcircle.com. Available at: https://www.alcircle.com/news/indiasmineable-bauxite-reserve-at-0656-bln-tonnescan-last-next-25-years-tifac-29156 (Accessed: 25 July 2018).
Husaini and Cahyono, S. S. (2009) 'Peningkatan kadar bijih bauksit Kijang dan Tayan dengan metoda scrubbing', Jurnal Teknologi Mineral dan Batubara, 5(4), pp. 147-162. Available at: https://jurnal.tekmira.esdm.go.id/index.php/ minerba/article/view/884.

Husaini, Suganal, Purnomo, H., Cahyono, S. S. Dahlan, Y., Amalia, D., Soenara, T. Supriyanto, B. A., Azhari, Ramanda, Y., Alamanda, N., Subiantoro, Wijaya, K., Erika, Fatimah, T. S., Sugandi, B., Pendi, S. and Permana, A. S. (2014) Pembuatan rancangan teknologi upgrading bauksit kapasitas 50 ton/jam. Bandung: Puslitbang tekMIRA.

King, H. M. (2017) Bauxite, geology.com. Available at: https://geology.com/minerals/bauxite.shtml (Accessed: 9 August 2018).

Nandi, A., Mahadevan, H. and Ramachandran, T. R. (2012) 'Bauxite-alumina industry of India', pp. 1-30.

Passos, E. R. and Rodrigues, J. A. (2016) 'The influence of titanium and iron oxides on the coloring and friability of the blue fired aluminum oxide as an abrasive material', Cerâmica, 62(361), pp. 38-44. doi: 10.1590/0366-69132016623611960.

Pusat Sumber Daya Geologi (2015) Executive summary pemutakhiran data dan neraca sumber daya mineral. Bandung: Badan Geologi.

Smith, P. (2008) 'Economic processing of high silica bauxites - Existing and potential processes', in High Silica Bauxite Processing. Parker Centre, CSIRO Light Metals Flagship, p. 42. Available at:

https://www.researchgate.net/publication/237 828211_Economic_Processing_of_High_Silic a Bauxites Existing_and_Potential_Processes.

Tsamo, C., Kofa, G. P. and Kamga, R. (2017) 'Decreasing yield and alumina content of red mud by optimization of the bauxite processing process', International Journal of Metallurgical Engineering, 6(1), pp. 1-9. doi: 10.5923/j.ijmee.20170601.01. 